\title{
Life Cycle of Cereal Cyst Nematode, Heterodera avenae on Resistant and Susceptible Barley Cultivars
}

\author{
Anshul Chhachhia* and R.S. Kanwar \\ Department of Nematology, CCS Haryana Agricultural University, Hisar-125004, India \\ *Corresponding author
}

\begin{abstract}
A B S T R A C T
Keywords

Heterodera avenae,

Barley, Life cycle,

Penetration and

Development

Article Info

Accepted:

17 November 2018

Available Online:

10 December 2018

The development of Heterodera avenae was studied on four resistant cultivars (BH 393, BH959, RD 2035 and DWRB 91) and one susceptible cultivar (BH902). After 20 days of germination inoculation was done with second stage juveniles@250 $\mathrm{J}_{2} /$ pot. Plants of each cultivar were uprooted at 15 days interval after the inoculation and observations were taken till adults were formed. Roots of uprooted plants were stained with $0.1 \%$ acid fuchs in lactophenol and observations on the development stages were taken by mounting the nematode dissected out of root in lactophenol. Penetration of the $\mathrm{J}_{2}$ of $H$. avenae was occurred insusceptible as well as in resistant cultivars but penetration was more in susceptible cultivars than resistant cultivars. In all the varieties, almost all the $\mathbf{J}_{2}$ could reach the fourth stage. Infected roots exhibited only slight swelling at the site of infection. $H$. avenae completed life cycle from $\mathrm{J}_{2}$ to female in 75 days on all varieties except, on $\mathrm{RD}$ 2035. Maximum number of cysts and cyst content was found in susceptible variety than resistant varieties but on RD 2035 no cysts were formed.
\end{abstract}

\section{Introduction}

Plant parasitic nematodes are among the most important groups of organisms affecting crop production. The cereal cyst nematode $(\mathrm{CCN}$, Heterodera avenae) is a destructive nematode pest on cereal crops worldwide and cause significant losses in many countries (Cook and Noel, 2002; Smiley and Nicol 2009; Dababat et al., 2015). In India, Vasudeva (1958) first reported it for the first time on wheat roots from Sikar district of Rajasthan and the disease caused by this nematode is commonly known as "Molya". In Haryana, Heterodera avenae has been reported from Mahendergard,
Sirsa, Ambala, Gurgaon, Rohtak, Bhiwani, Faridabad and Hisar districts of Haryana (Kanwar et al., 2011). Bird and Kaloshian (2003) estimated that these obligate parasites causing over 100 billion dollars annual crop losses. Abad et al., (2008) estimated worldwide crop losses caused by nematodes to be $\$ 157$ billion per annum.

Barley (Hordeum vulgare) is a main grain crop which is consumed in various forms. In Haryana, the production of barley is 0.14 million tons on 40,000 hectares (Anonymous, 2017). Van Berkum and Seshadri (1970) calculate losses worth Rs. 60 million in wheat 
and barley in Rajasthan state only and also estimated losses of Rs 255 lakh for barley in three districts of Rajasthan alone. In 1960s, CCN caused losses worth Rs. 40 million and Rs. 30 million in wheat and barley, respectively in Rajasthan. The annual loss caused in wheat has been estimated to the tune of Rs. 66 crores in Haryana alone (Kanwar et al., 2007). Resistance in cereals against Heterodera avenae may operate at different levels. With the findings resistance in barley many workers traced the nature of resistance. Andersen (1961) observed that the larvae, which invaded the roots of resistant plants, did not mature into females. The adult females of $H$. avenae remained small sized and failed to extrude from the roots and, were, thus unable to copulate and reproduce on barley cultivar C-164 (Bajaj et al.,1996). Barley varieties BP 262, BP 264 and C-164 were found resistant to $H$. avenae and ratio of male to female was 106:1, 86:1, and 109:1, respectively (Bhatti et al., 1976). Some resistant cultivars of barley like Rajkiran, RD 2052, RD 2035, RD 2508, BH-331, BH-338 and C-164 have been developed and released for cultivation in Molya prone areas of these states (Anon., 1979; Singh et al., 2000). Therefore further investigations were planned on some aspects of the life cycle and development of Heterodera avenae on some barley varieties.

\section{Materials and Methods}

Seeds of five barley cultivars, susceptible $(\mathrm{BH}$ 902) and resistant (BH 393, BH959, RD 2035, DWRB 91) were obtained from the stock maintained in the Department of Plant breeding \& genetics, CCS HAU, Hisar and sown in $15 \mathrm{~cm}$ diameter earthen pots filled with steam sterilized soil having $\mathrm{pH} 8.5$ and EC 0.05. After germination one plant per pot was retained. Each treatment was replicated thrice. The juveniles were obtained by incubating the cysts in distilled water at $10^{\circ} \mathrm{C}$ for 30 days and collecting $\mathbf{J}_{2}$ every third day and after 20 days of germination inoculation of larvae was done @ $250 \mathrm{~J} 2$ / pot. Inoculation was done by carefully removing the soil around the roots of plants in each pot to ensure direct and easy approach of juveniles to root system. The larval suspension was bubbled continuously for 10-15 seconds for required quantity and poured on exposed root system with pipette. Plants of each cultivar were uprooted at 15 days interval after the inoculation and observations were taken till adults were formed. Roots of uprooted plants were stained in $0.1 \%$ acid fuchs in lactophenol (McBerth et al., 1941) and observations on the development stages were taken by mounting the nematode dissected out of root in lactophenol. The soil of each pot was processed through a 60 mesh sieve placed over a 300 mesh sieve by Cobb's decanting and sieving technique. White females and cysts remaining on the 60 mesh sieves were further processed by Baermann's funnel technique for the recovery of males.

\section{Results and Discussion}

The Penetration of second stage juveniles of Heterodera avenae occurred in susceptible as well as resistant cultivars of barley (Table 1). However, the penetration was more in susceptible cultivar than resistant cultivars (Fig. 1). The development of Heterodera avenae differed in the susceptible and resistant cultivars (Fig. $4 \mathrm{C}$ and D). In case of susceptible variety (BH 902), third stage was observed on 30th day of inoculation. Infected roots exhibited slight swelling and lateral branching and at the site of infection (Fig. 4 E). Fourth stage females were recorded from 45 th day onwards. Adults (males and females) were observed after 60 days of inoculation from soil and roots, respectively. Root tissues near the head of juveniles exhibited necrosis in the form of black spots (Fig. 4 F). 
Table.1 Penetration and Developmental stages of Heterodera avenae in roots and soil of resistant and susceptible varieties of barley Days after inoculation

\begin{tabular}{|c|c|c|c|c|c|c|c|c|c|c|}
\hline \multirow{3}{*}{$\begin{array}{l}\text { Days after } \\
\text { inoculation }\end{array}$} & \multicolumn{8}{|c|}{ Resistant varieties } & \multirow{2}{*}{\multicolumn{2}{|c|}{$\begin{array}{c}\text { Susceptible variety } \\
\text { BH } 902\end{array}$}} \\
\hline & \multicolumn{2}{|c|}{ ВH 393} & \multicolumn{2}{|c|}{ ВH 959} & \multicolumn{2}{|c|}{ RD 2035} & \multicolumn{2}{|c|}{ DWRB 91} & & \\
\hline & Root system & Soil & $\begin{array}{c}\text { Root } \\
\text { system }\end{array}$ & Soil & $\begin{array}{c}\text { Root } \\
\text { system }\end{array}$ & Soil & $\begin{array}{c}\text { Root } \\
\text { system }\end{array}$ & Soil & $\begin{array}{c}\text { Root } \\
\text { system }\end{array}$ & Soil \\
\hline 15 & $22 \mathbf{J}_{2}$ & - & $14 \mathrm{~J}_{2}$ & - & $10 \mathrm{~J}_{2}$ & - & $17 \mathrm{~J}_{2}$ & - & $43 \mathrm{~J}_{2}$ & - \\
\hline 30 & $2 \mathrm{~J}_{2}, 19 \mathrm{~J}_{3}$ & - & $12 \mathrm{~J}_{3}, 1 \mathrm{~J}_{2}$ & - & $7 \mathrm{~J}_{3}, 2 \mathrm{~J}_{2}$ & - & $14 \mathrm{~J}_{3}, 2 \mathrm{~J}_{2}$ & - & $3 \mathrm{~J}_{2}, 36 \mathrm{~J}_{3}$ & - \\
\hline 45 & $\begin{array}{c}1 \mathrm{~J}_{3}, 9 \mathrm{~J}_{4} \circlearrowright^{\hat{O}}, 8 \\
\mathrm{~J}_{4}+\end{array}$ & - & $\begin{array}{c}1 \mathrm{~J}_{3}, 6 \mathrm{~J}_{4} \bigcirc^{\lambda}, \\
5 \mathrm{~J}_{4}+\end{array}$ & - & $\begin{array}{c}1 \mathrm{~J}_{3,}, 4 \mathrm{~J}_{4} \hat{\bigcirc}, 2 \\
\mathrm{~J}_{4} \uparrow\end{array}$ & - & $\begin{array}{c}1 \mathrm{~J}_{3}, 9 \mathrm{~J}_{4} \hat{O}^{1} \\
4 \mathrm{~J}_{4}+\end{array}$ & - & $\begin{array}{c}2 \mathrm{~J}_{3}, 28 \mathrm{~J}_{4}+ \\
7 \mathrm{~J}_{4} \hat{0}\end{array}$ & - \\
\hline 60 & $6 \mathrm{~J}_{4}$ ㅇ & $7 \hat{0}$ & $3 \mathbf{J}_{4}$ ㅇ & $30^{\pi}$ & $1 \mathbf{J}_{4}$ ㅇ & 20 & $3 \mathbf{J}_{4}$ ㅇ & 50 & $25 \mathrm{~J}_{4}+, 2$ ㅇ & $40^{\pi}$ \\
\hline 75 & 2 우 & 29 & - & $2 q$ & 0 우 & - & 0 & 1 우 & s11q & 8 ㅇ \\
\hline
\end{tabular}

$\mathbf{J}_{2}=$ Second stage juvenile, $\mathbf{J}_{3}=$ Third stage juvenile, $\mathbf{J}_{4} \uparrow=$ Fourth stage female juvenile, $\mathbf{J}_{4} \hat{\delta}=$ Fourth stage male juvenile, $q=$ Adult female, $\hat{O}=$ Adult male 
Fig.1 Total number of nematode penetration after 15 days of inoculation in resistant and susceptible

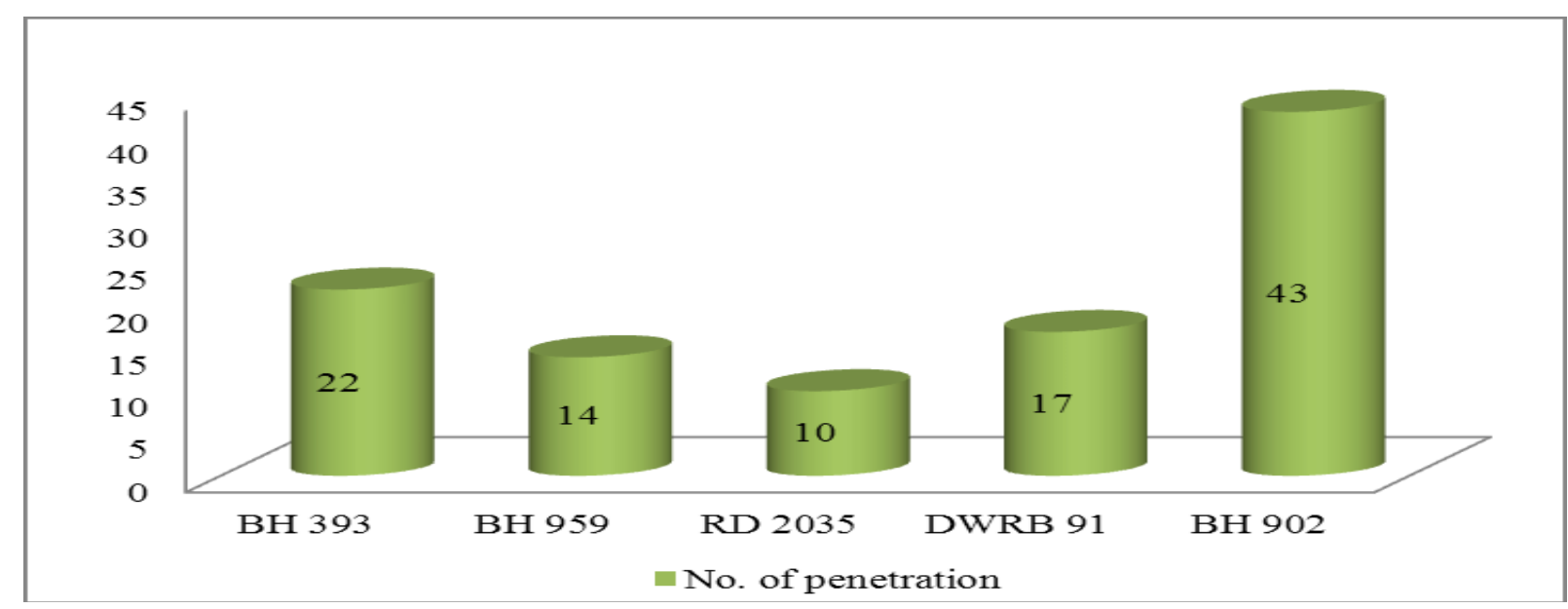

Fig.2 Total number of cyst formed per plant on different barley varieties

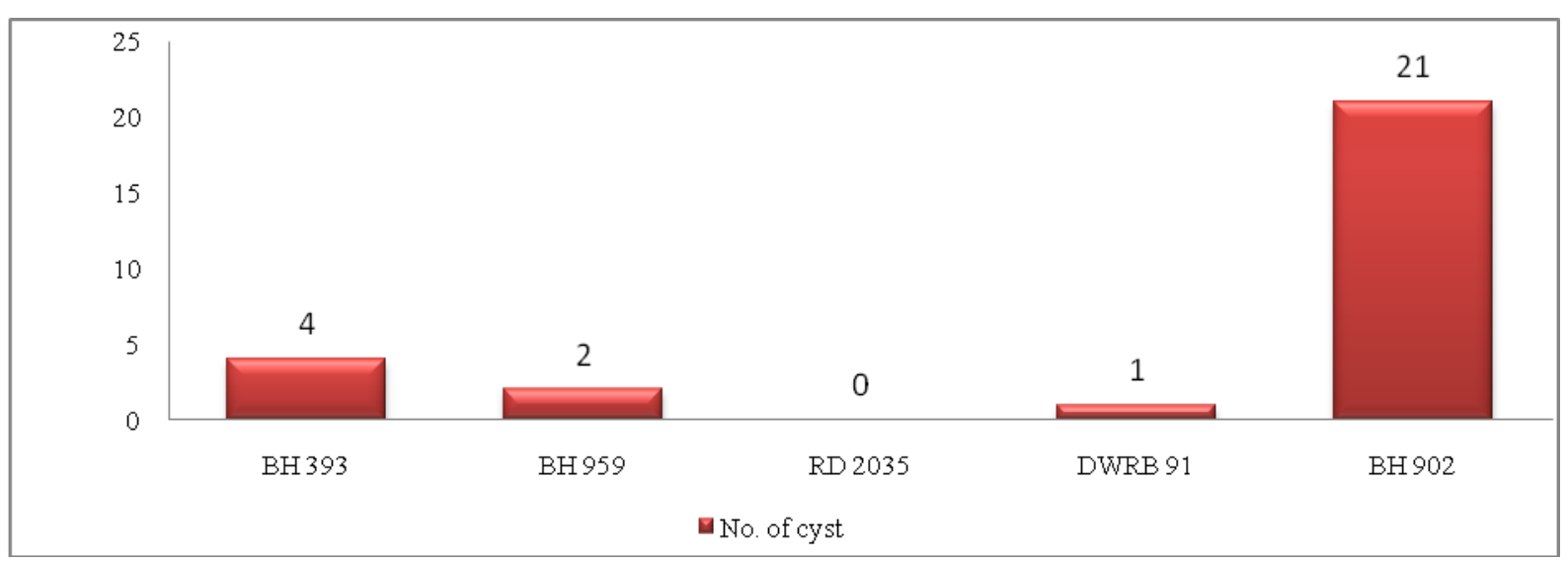


Fig.3 Average cyst content in different varieties of barley varieties

\begin{tabular}{|c|c|c|c|c|c|}
\hline 250 & \multirow[b]{2}{*}{210} & \multirow[b]{2}{*}{200} & & \multirow[b]{2}{*}{190} & \multirow[t]{2}{*}{235} \\
\hline 200 & & & & & \\
\hline 150 & & & & & \\
\hline 100 & & & & & \\
\hline 50 & & & 0 & & \\
\hline & BH 393 & $\begin{array}{r}\text { BH } 959 \\
\text { No. of }\end{array}$ & $\begin{array}{l}\text { RD } 2035 \\
\text { nts }\end{array}$ & DWRB 91 & BH 902 \\
\hline
\end{tabular}

Fig.4 Penetration of J2 after 30 days of inoculation in susceptible variety (A) and resistant variety (B), Developmental stages of Heterodera avenae in susceptible variety (C) and resistant variety (D), Swelling of root (E) and syncytium formation at the feeding site of nematode penetration $(\mathrm{F})$.

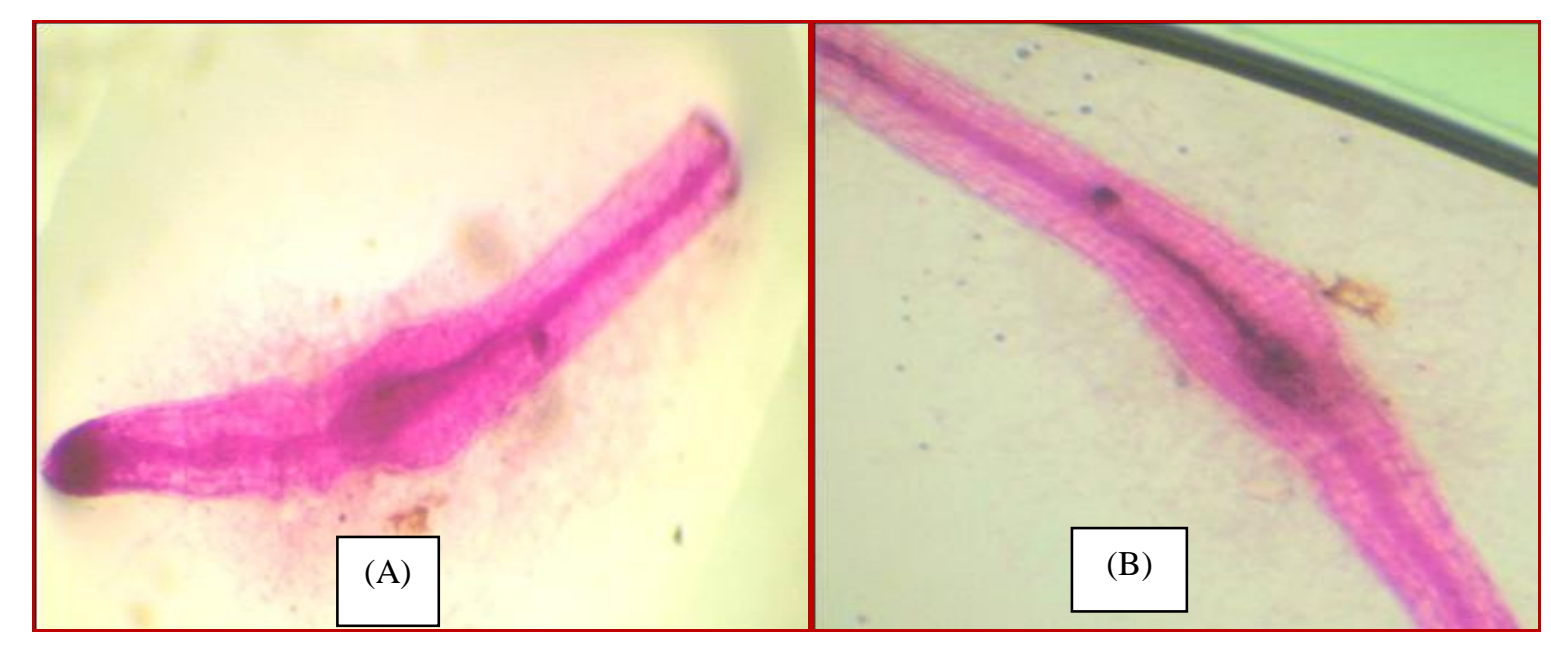


Int.J.Curr.Microbiol.App.Sci (2018) 7(12): 2392-2400

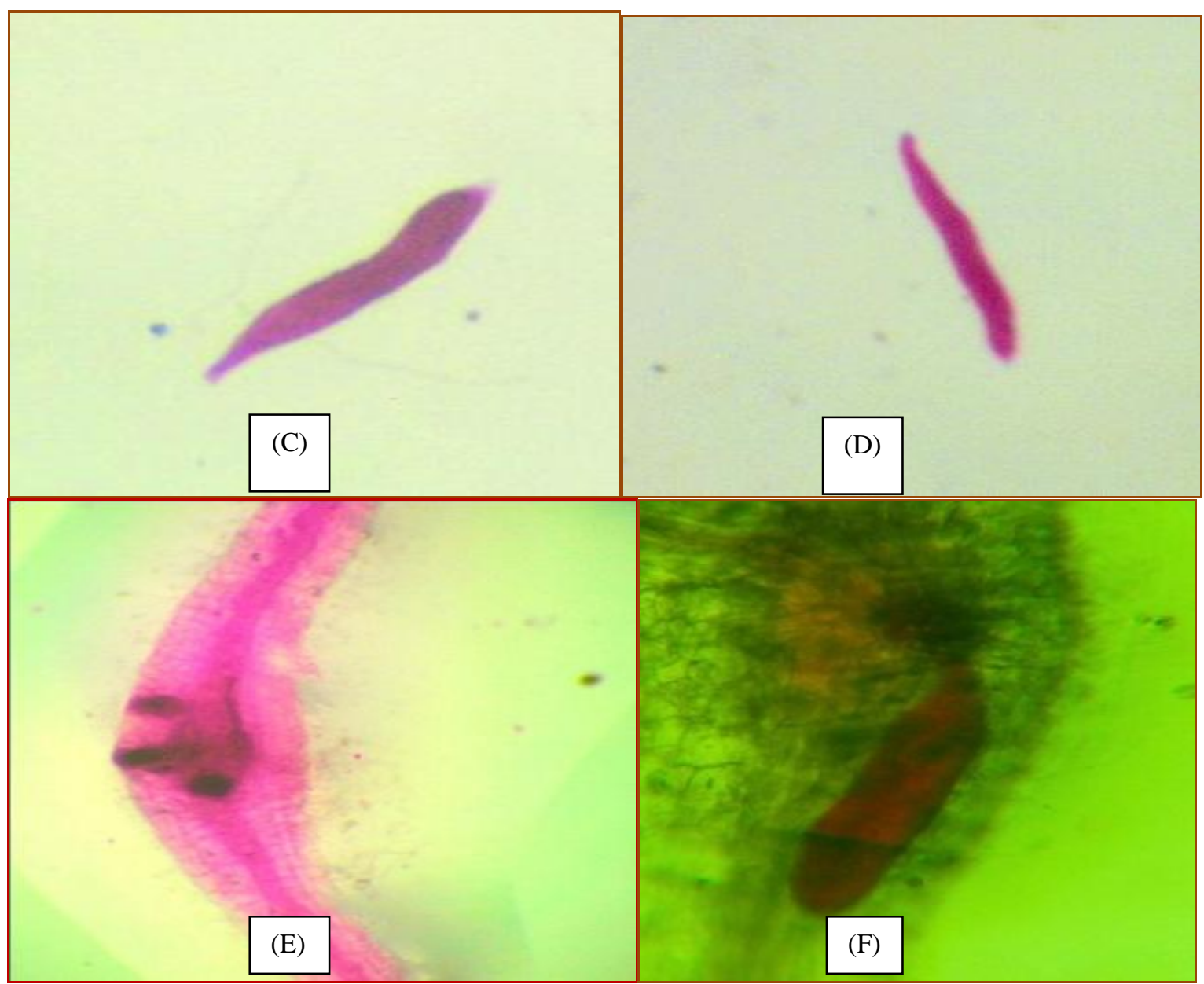


In all the varieties, almost all second stage juveniles could reach the fourth stage. Infected roots exhibited only slight swelling at the site of infection. However, males were able to reach adulthood but the development was comparatively slow. In RD 2035, no female or cyst was produced while in other varieties less number of cysts, as compared to the susceptible one, was formed (Table 1). In RD 2035, the fourth stage juveniles of female failed to develop further in the roots and got disintegrated at this stage itself. Comparatively, cyst formed earlier in susceptible variety than the resistant varieties. A good number of males were recorded in resistant varieties indicating that male development was not much affected which led to change in male: female ratio in favour of males as compared to susceptible check. Heterodera avenae completed life cycle from $\mathrm{J}_{2}$ to female in 75 days on all varieties except, on RD 2035 although less females developed on resistant varieties.

Maximum number of cysts (21) was found on BH 902 than other resistant varieties (Fig. 2). The average cyst content was estimated by dilution method. The cyst content was found 210, 200, 190 and 235 on varieties BH 393, BH 959, DWRB 91 and BH 902 respectively. No cyst content could be recorded in variety RD 2035 as no cyst was formed on it. The highest cyst content was found in the susceptible variety (Fig. 3). Fewer numbers of juveniles penetrated the resistant cultivars than susceptible cultivar. There are several studies which reported less nematode penetration in resistant varieties (Bishnoi et al., 2008; Price et al., 1983). This is chiefly due to the difference in chemicals exuded from roots of resistant and susceptible plants. Less penetration of endoparasites or exodus from roots is due to pre-inflectional resistance in the host plant. Further development of Heterodera spp. depends upon successful establishment of feeding sites (syncytia) in the host in absence of which nematode development is seized or adversely affected Among resistant cultivars, in RD 2035 lesser number of juveniles that had penetrated the roots reached to $J_{3}$ and $J_{4}$ stages but no further development was observed. In this variety, no female or cyst was produced while in other resistant varieties very less number of cysts as compared to the susceptible one were formed. RD 2052 had a different type of resistant mechanism than reported for C-164 (Bajaj et al., 1996) where development was normal up to adult female stage. However, such females remained small sized and failed to protrude out of roots and copulate.

In resistant varieties, penetration was less as compared to the susceptible one. Similar observation was made by Bishnoi et al., (2008) who indicated that maximum number of $J_{2}$ penetrated in susceptible barley variety RD 103 while lesser in resistant variety RD 2052 and RD 2035. They recorded good number of males in RD 2052 indicating that males development was not much affected which led to change in male: female ratio in favour of males as compared to susceptible check.

Maximum numbers of cysts (21) were found on susceptible barley BH 902. On resistant varieties, less number of cysts (1-4 per plant) developed except on RD 2035, where no cyst was formed. The size of cyst formed in $\mathrm{BH}$ 902 variety was larger as compared to the resistant varieties. Bishnoi et al., (2008) reported small size white cysts without eggs on RD 2052 and RD 2035 barley varieties. Production of small-sized cysts with few eggs by cereal cyst nematodes on resistant hosts is a common phenomenon (Cook and Mizen, 1991; Bajaj et al., 1996; Kanwar et al., 2004).

\section{References}

Abad, P., Gouzy, J., Aury, J.M., and Castagnone-Sereno, P. (2008).Genome 
sequence of the metazoan plantparasitic nematode Meloidogyne incognita. Nature Biotechnology, 26, 909-915.

Andersen, S. (1961). Resistance mod havreal, Heterodera avenae.Med.68 Kge. Vet. Land Haisk, Kobenhaven, pp. 179.

Anonymous (1979).Annual Report of Wheat and Barley. All India Coordinated Research Project on Wheat and Barley Improvement, ARS, Durgapura, Jaipur, pp. 17-29.

Anonymous (2017).Progress report of All India Coordinated Wheat and Barley Improvement Project 2016-17, Project Director's Report.Ed. G.P. Singh, ICAR-Indian Institute of Wheat and Barley Research, Karnal, India.pp. 87.

Bajaj, H.K., Dahiya, R.S. and Dalai, M.R. (1996). Development of Heterodera avenaebiotype $\mathrm{Ha} 31$, on resistant barley and oat cultivars. Nematologia Mediterranea, 24, 53-57.

Bhatti, D.S., Dhaiya, R.S., Dalal, M.R. and Dhawan S.C. (1976). Resistant barley varieties for the control of Heterodera avenae Wollenweber 1924. Current Science, 45, 678.

Bird, D.M. and Kaloshian, I. (2003). Are roots special? Nematodes have their say. Physiological and Molecular Plant Pathology, 62, 115-123.

Bishnoi, S.P., Yadav, S.M. and Chand, R. (2008).Response of resistant cultivars of wheat and barley to Heterodera avenae. Indian Journal of Nematology, 38(1), 110-111.

Cook, R. and Mizen, K.A. (1991). Expression of resistance in oat (Avenaspp.) and some other cereals to cereal cyst nematode (Heterodera avenae). Helminthologia, 28, 145-150.

Cook, R. and Noel, G.R. (2002). Cyst nematodes: Globodera and Heterodera species. In: 'Plant Resistance to Parasitic Nematodes'. (Eds. JL Starr, R
Cook, J Bridge), (CABI Publishing, Wallingford, UK). pp. 71-105.

Dababat, A.A., Imren, M., Erginbas-Orakci, G., Ashrafi, S., Yavuzaslanoglu, E., Toktay, H., Pariyar, S.R., Elekcioglu, H., Morgounov, A. and Mekete, M. (2015). The importance and management strategies of cereal cyst nematodes, Heterodera spp., Turkey. Euphytica, 202, 173-188.

Kanwar, R.S., Bajaj, H.K. and Vats, R. (2004). Development of Heterodera filipjevi on wheat varieties resistant to Heterodera avenae. Indian Journal of Nematology, 34(2), 205-238.

Kanwar, R.S., Nandal, S.N., Paruthi, I.J. and Bajaj, H.K. (2007). National Symposium on Nematology in $21^{\text {st }}$ century: emerging paradigms. Proc 7 th National Symposium on Nematology. Assam Agricultural University, Jorhat, Assam, pp. 40.

Kanwar, R.S., Nandal, S.N., Paruthi, I.J. and Bajaj, H.K. (2011). Status of Heterodera aveane Woll. and losses caused by it in wheat in Haryana state of India. Haryana Agricultural University Journal of Research, 41, 2123.

McBerth, C.W., Taylor, A.L. and Smith, A.L. (1941). Note on staining nematodes in root tissues. Proceedings of the Helminthological Society of Washington, 16, 3-6.

Price, N.S., Clarkson, D.T. and Hague, N.M. (1983).Effect of invasion by cereal cyst nematode (Heterodera avenae) on the growth and development of the seminal roots of oats and barley. Plant Pathology, 32(4), 377-383.

Singh, D., Malik,V. and Kumar, K. (2000). Present status and future strategies in barley breeding during new millennium. In Plant Breeding Prespectives in Third Millennimum Eds. BPS Lather, S.S. Dhanda and Prakash Kumar, HAU 
Press, Hisar, pp. 68-78.

Smiley, R.W. and Nicol, J.M. (2009) Nematodes which challenge global wheat production. In: 'Wheat Science and Trade.' (Ed. BF Carver), (WileyBlackwell, Ames Iowa, USA), pp. 171-
187.

Van Berkum, J.A. and Seshadri, A.R. (1970). Some important nematode problems in India (Abstract). Xth International Nematological Symposium Pescara, Italy. pp. 136-137.

\section{How to cite this article:}

Anshul Chhachhia and Kanwar, R.S. 2018. Life Cycle of Cereal Cyst Nematode, Heterodera Avenae on Resistant and Susceptible Barley Cultivars. Int.J.Curr.Microbiol.App.Sci. 7(12): 2392-2400. doi: https://doi.org/10.20546/ijcmas.2018.712.271 